REVIEW

\title{
Genetics and health inequalities: hypotheses and controversies
}

\author{
Johan P Mackenbach
}

J Epidemiol Community Health 2005;59:268-273. doi: 10.1136/jech.2004.026807

This article reviews the current understanding of the explanation of socioeconomic inequalities in health in industrialised countries and then tries to determine where genetic factors could fit into explanatory schemes. It focuses on the explanation of socioeconomic inequalities in frequency of the main health problems of middle and old age.

Correspondence to: Professor J P Mackenbach, Department of Public Health, Erasmus MC, University Medical Center Rotterdam, PO Box 1738 3000 DR Rotterdam, Netherlands; i.mackenbach@ erasmusmc.nl

Accepted for publication 3 September 2004
$\mathrm{S}$ ocioeconomic inequalities in health are one of the important challenges for public health in developed countries. In all countries with available data, substantial inequalities have been found that amount to a difference of several years of life expectancy between those with higher and lower levels of education, occupation, or income. ${ }^{12}$ During the past decade, important progress has been made with explaining these health inequalities. An understanding of health inequalities in terms of the main contributory factors has emerged, and several theoretical models have been proposed that summarise this understanding..$^{3-6}$

These models usually ignore genetic factors as possible contributors to explanations of health inequalities. This reflects the fact that very little effort has until now been made to empirically investigate the role of genetic factors. This is partly attributable to a lack of opportunity for such investigations, but this situation is changing: knowledge of the role of genetics in disease causation is increasing, genetic tests are becoming available and are being assessed for their clinical and epidemiological significance, and large bio-banks are being created in several countries. It is therefore important to assess the plausibility of various hypotheses about the role of genetic factors in the explanation of health inequalities.

It is by no means clear how genetic factors could contribute to the explanation of health inequalities. There is no doubt that genetic factors are important determinants of betweenindividual differences in disease risks, as shown indirectly by substantial degrees of "heritability" in twin and adoption studies*, or more directly by associations between genetic markers or candidate genes and the occurrence of disease or risk factors for disease. But such genetic factors can only contribute to differences in disease risk between groups of people (in this case: classified by a marker of socioeconomic status), if their prevalence differs systematically between these groups.
This commentary addresses this difficulty. I will briefly review the current understanding of the explanation of socioeconomic inequalities in health in industrialised countries, and then try to determine where genetic factors could fit into explanatory schemes. I will focus on the explanation of socioeconomic inequalities in frequency of the main health problems of middle and old age. Dealing with the underlying biological mechanisms is, of course, outside the scope of this paper. For basic terms and concepts the reader is referred to a recent "Glossary" published in this journal. ${ }^{7-9}$

\section{CURRENT UNDERSTANDING OF THE EXPLANATION OF HEALTH INEQUALITIES} Current understanding of the explanation of socioeconomic inequalities in health can best be characterised as multifaceted. Research findings can be grouped into a number of complementary perspectives: the "specific determinants" perspective, the "selection" perspective, and the "life course perspective". ${ }^{10}$

The "specific determinants" perspective Any causal effect of socioeconomic position on health is likely to be mainly indirect, through differential exposure to a number of more specific determinants. This causal effect arises when socioeconomic status determines a person's behaviour, living circumstances, healthcare use, etc, and when these specific determinants induce a higher or lower frequency of health

* "Heritability" is the ratio between the "genetic variability" and the total variability that is observed between individuals for a certain trait, or the proportion of a trait's variation within a specified population that can be attributed to genetic differences. Heritability ranges between 0 and 1 , with 1 indicating that all of the interindividual variation in a certain characteristic can be attributed to genetic variation. Heritability is estimated in studies in which systematic comparisons are made between individuals in similar family environments that are known to share their genetic make up to various degrees (such as monozygotic and dizygotic twins, or non-adopted and adopted children), and between genetically similar individuals that are known to share their family environment to various degrees (such as monozygotic twins reared together or apart). The assumptions made in estimating heritability from such studies may not always be correct. In research on twins, for example, it is assumed that twins who are reared together have identical environments, so that greater similarity between monozygotic and dizygotic twins can be interpreted as reflecting differences in genetic make up. This is not necessarily true, however, because monozygotic twins look more alike than dizygotic twins, and may therefore be treated more alike. (Adapted from Atkinson et $a{ }^{48}$ ). 
problems. The main groups of determinants that have been identified empirically as playing an important part in the explanation of health inequalities are material and psychosocial circumstances and behavioural and biological factors. ${ }^{5}$ 10-12

Material circumstances include determinants linked to the physical environment (for example, working and housing conditions) as well as economic hardship..$^{14}$ Psychosocial circumstances include psychosocial stressors (for example, life events, job strain) and lack of social support. ${ }^{15} 16$ Behavioural factors include smoking, diet, alcohol consumption, and lack of physical exercise. ${ }^{17-19}$ These three groups of factors are themselves interrelated: material factors may act as a source of psychosocial stress, and psychosocial stress may influence health related behaviour. ${ }^{20}$ Each of the three influences health through specific biological factors. A diet rich in saturated fat will lead to atherosclerosis, which will increase the risk of a myocardial infarction. Psychosocial stress will activate hormonal systems that may increase blood pressure and reduce the immune response. ${ }^{5}$

Undoubtedly, different levels of exposure of lower socioeconomic groups to these determinants are the main explanation of health inequalities. Typically, multivariate analyses of longitudinal studies including socioeconomic status, a range of determinants, and one or more objective health outcomes suggest a total contribution of between $40 \%$ and $70 \%,{ }^{21}{ }^{22}$ which in view of inevitable measurement errors should be seen as a very sizable contribution. What is less clear, perhaps, is the extent to which different levels of exposure of lower socioeconomic groups to these determinants reflect a causal effect of socioeconomic status. In most studies, exposure to these determinants is measured at baseline, together with socioeconomic status. In the case of behavioural factors, for example, it is difficult to exclude the possibility that differences between socioeconomic groups are partly attributable to differences in personal attributes that were already present before people obtained their educational or occupational positions, and that also influenced their social careers.

\section{The "selection" perspective}

Selection explanations imply that health (or a determinant of health) determines socioeconomic position, instead of socioeconomic position determining health. These selection mechanisms depend on the occurrence of social mobilitythat is, changes in socioeconomic position during a person's lifetime, compared either with their parents (intergenerational) or with the person at an earlier point in time (intragenerational). Research on social mobility has shown that intergenerational social mobility has indeed been quite common and rising over the past century in all Western countries, with proportions of men who have a higher or lower occupational class than their fathers being in the order of $50 \% .^{23}$ Upward mobility has occurred much more commonly than downward mobility, because of the modernisation of the workforce and the expansion of educational opportunities, a development that is also seen in increased rates of intergenerational educational mobility. ${ }^{25}$ Intragenerational mobility between occupational or educational classes is much less common, but "mobility" within an adult's lifetime between income classes occurs quite often. ${ }^{26}$

There is some evidence that (ill)health is indeed a determinant of social mobility, with people in poor health being less likely to move upward or more likely to move downward in socioeconomic position. ${ }^{27}{ }^{28}$ However, the rather scarce research findings show that its contribution to the explanation of health inequalities is small. This applies to both intergenerational and intragenerational social mobility. ${ }^{27-29}$ This is attributable to the fact that most health problems arise at ages when social mobility has become rare. Moreover, some studies actually show that health related selection during social mobility constrains (instead of increases) health inequalities, because those that are downwardly mobile because of worse health than others in their class of origin, at the same time tend to have better health than others in their class of destination. ${ }^{30}$

While the impact of such "direct selection"-that is, selection on health-is likely to be small, particularly when educational level or occupational class are used as indicators of socioeconomic status, there is more uncertainty about (but also more scope for) an impact of "indirect selection". This mechanism implies that social mobility is selective on determinants of health, not on health itself. ${ }^{31}{ }^{32}$ While this may apply to any determinant, the main hypothesis concerns personal attributes such as cognitive ability, coping styles, control beliefs, personality, and bodily and mental fitness that may influence educational and occupational achievement, and at the same time determine later health, either directly or through health related behaviours such as consumption and exercise patterns and use of health services. $^{31}{ }^{32}$ Empirical studies have found associations between many of the personal attributes mentioned above and social mobility. ${ }^{33-36}$ Some multivariate analyses suggest that these personal attributes do indeed contribute to the explanation of health inequalities. ${ }^{36-38}$

\section{The "life course" perspective}

The life course perspective integrates different explanations into one coherent framework that allows for the time dependency of effects over a person's lifetime, and for reciprocity of relations between "determinants" and "health outcomes". ${ }^{39}{ }^{40}$ Empirical support for this perspective is still limited, and consists mainly of demonstrations of the importance of early life exposures to socioeconomic disadvantage or specific health determinants to later life health outcomes. ${ }^{41-43}$ Nevertheless, the conceptual potential of this explanatory perspective is huge. For example, it has been useful in bringing together elements from "selection" and from "causation" explanations. One important illustration is in the field of "indirect selection". Whether the direction of the association between personal attributes possibly involved in indirect selection, and socioeconomic status is mainly from personal attributes to socioeconomic status, as the "indirect selection" hypothesis implies, or vice versa, has not been established. ${ }^{12}{ }^{32}$ The characteristics on which indirect selection occurs could either be innate characteristics that are independent from the circumstances in which individuals grow up, or factors that are largely determined by socioeconomic and other circumstances in early life. In the latter case, the life course perspective would suggest that indirect selection is actually part of a larger story of accumulating social causation. ${ }^{29}$

\section{POSSIBLE ROLE OF GENETIC FACTORS}

Genotype will play a part in explaining health inequalities if (1) socioeconomic status is associated with one or more genotypes, and (2) those genotypes are themselves causally involved in the occurrence of health problems, either directly (by an effect on the occurrence of disease) or indirectly (by an effect on determinants of disease). Both conditions must be fulfilled.

\section{The "specific determinants" perspective}

How could genes predisposing for certain diseases or their determinants become differentially distributed across socioeconomic groups? Genetic factors do not easily fit into a "causation through specific determinants" framework, because temporally a person's genotype precedes their socioeconomic status, and a causal effect of the latter on the first is 
therefore logically impossible. To accommodate genetic factors, it would be necessary to extend this framework and include intergenerational influences-that is, effects of forefathers' socioeconomic status on the health of offspring through an effect on genotype. This is not entirely impossible, as suggested by the association between parents' socioeconomic status and some non-chromosomal congenital anomalies. ${ }^{44}$ Some of these associations may be attributable to effects of parental exposure on germline genetic material, but the aetiology of most of the cases of congenital anomaly remains unknown. It is probable that most of the excess congenital anomalies in lower socioeconomic groups arise through exposures to noxious influences during pregnancy (for example, inadequate nutrition, smoking and alcohol consumption, occupational exposures). A well known example is that of neural tube defects caused by inadequate consumption of folic acid. ${ }^{44}$

\section{The "selection" perspective}

Genetic factors can more easily be seen to operate within a "selection" framework.

An association between socioeconomic status and a certain genotype will arise when the genotype is a determinant of social mobility, either through an effect on health status (direct selection) or through an effect on personal attributes related to social mobility (indirect selection). As we have seen above, direct selection is unlikely to play a more than marginal part, but the verdict on indirect selection is still largely open. To the extent that personal attributes that influence social mobility (cognitive ability, coping styles, control beliefs, personality, bodily and mental fitness, ...) are

\section{Key points}

- Genetic factors have usually been ignored in studies investigating the explanation of socioeconomic inequalities in health. If the rising opportunities for doing genetic research are to be used wisely, it is important to phrase the right questions about the role of genetic factors in explaining health inequalities.

- Genotype will play a part in explaining health inequalities if (1) socioeconomic status is associated with one or more genotypes, and (2) those genotypes are themselves causally involved in the occurrence of health problems.

- The most plausible mechanism through which genes predisposing for certain diseases or their determinants become associated with socioeconomic status is through an influence of genotype on intergenerational social mobility.

- The most plausible specific hypotheses relate to the genetic determinants of personal attributes (cognitive ability, personality, bodily and mental fitness, ...) that influence educational and occupational achievement, and also determine adult health, either directly or through health related behaviours.

- There is still very little empirical evidence in this area. Decisions on allocation of research funds to research into genetic determinants of health inequalities should be based on a careful assessment of risks and potential benefits. If such research is conducted, it is important to put into place a number of safeguards that minimise the risks, perhaps to be derived from existing bioethical guidelines for behavioural genetics research. genetically co-determined, the underlying genotypes will tend to be more common in the upper or lower social classes.

Are personal attributes that are associated with social mobility genetically co-determined? Research in behavioural genetics suggests that in addition to environmental factors genetic factors indeed also play a part, particularly in the case of (general) intelligence, personality and height (as an indicator of bodily fitness).

For intelligence, combination of the results of family, adoption, and twin data from the United States and Western Europe has produced a heritability estimate of around 0.50 , with a range of possible values from 0.35 to $0.75 .^{45-47}$ This shows that in the populations (and environments) studied, about half of the variation in intelligence between people can be ascribed to variations in genetic make up. Some progress has been made in identifying genes associated with variations in intelligence in the normal range. Different alleles of the insulin-like growth factor 2 receptor (IGF2R) gene are associated with different levels of intelligence. ${ }^{46}$ Association studies have also suggested that the APOE-4 and catechol-omethyltransferase (COMT) genes are involved, but these findings have not been replicated. ${ }^{47}$ Associations between intelligence and intergenerational social mobility, controlling for family background, have also been reported. ${ }^{33} 3448$

Personality is defined as the "distinctive and characteristic patterns of thought, emotion and behavior that define an individual's personal style and influence his or her interaction with the environment". ${ }^{48}$ There is clear evidence for a role of genetics in the "big five", a set of five "trait dimensions" that together are thought to represent interindividual variations in personality: neuroticism, extraversion, conscientiousness, openness to experience, and agreeableness. Heritability estimates from twin studies for these traits range from 0.30 to $0.50 .{ }^{47-49}$ Although some gene variants have been implicated, no definitive conclusions can yet be drawn. ${ }^{47-49}$ Associations between personality and intergenerational social mobility have also been reported. ${ }^{33} 3448$

For height, heritability estimates from twin, sibling, and adoption studies have varied between 0.40 and $0.90 .^{50}$ It is probable that the contribution of genetic factors is not constant across environments: the relative contribution of environmental factors to interindividual differences in height is probably larger in poorer, and smaller in richer environments. Perhaps in modern Western populations heritability of height is as high as $0.80 . .^{50}$ A number of different genes have been implicated, including the IGFl gene.. ${ }^{52}$ Associations between height and intergenerational social mobility have also been reported. ${ }^{31} 3536$

It is important to note that this mechanism, in which an association between genotype and socioeconomic status arises through selection during intergenerational social mobility, does not presuppose that these personal attributes are transmitted from parent to child, and within socioeconomic status groups from one generation to the next. Take the example of intelligence: this is a complex trait that is probably determined by multiple genes (and multiple environmental characteristics, as well as interactions between and among the two). ${ }^{45-47}$ There is considerable "assortative mating" (studies have found the correlation between the intelligence of marriage partners to be about 0.40 ), so some degree of transmission of genetic determinants of intelligence is plausible. ${ }^{46}$ It is unlikely, however, that a complete set of genes associated with a high level of intelligence is transmitted intact from parent to child, because the relevant genes are located on different chromosomes and will become reassorted during meiosis. Even if this reassortment occurs, some children will have a certain constellation of genes that is associated with higher or lower 
intelligence, which then helps them in gaining higher social positions, while others have not. The same applies to other personal attributes that are genetically co-determined. After a small number of generations, the descendants of those possessing the trait will possess all possible genotypes, ${ }^{53}$ and the continued association between genotype and socioeconomic status will be dependent on continued selection during social mobility in each new generation

If intergenerational transmission of these phenotypic characteristics within socioeconomic groups is infrequent, and if the association between certain genotypes and socioeconomic status has to be produced through social mobility in every generation, then any such associations are likely to be modest in magnitude. Nevertheless, the hypothesis emerging from these considerations is that the main contribution of genetic factors in the explanation of health inequalities is likely to be through personal attributes influencing social mobility.

\section{The life course perspective}

As described above, scientific debates about the relative importance of the "(causation through) specific determinants" perspective and the "selection" perspective were partly resolved by the life course approach, which showed that both mechanisms could operate to strengthen each other and to lead to accumulation of social and health disadvantage over the life course. If evidence on the role of genetics in health inequalities would become available in the future, life course models are again likely to provide a good framework for integrating such new evidence into the larger body of evidence on the role of the environment in explaining health inequalities.

Within this framework, genetic factors predisposing to health problems can be seen as a form of disadvantage that can accumulate with other forms of disadvantage over the life course. The sophistication of current thinking about geneenvironment interaction, including notions such as "active genotype-environment correlation", ${ }^{46}{ }^{48}$ will provide opportunities for further refinement of the framework. It is probable that people with certain personal attributes (intelligence, personality, ...) actively seek environments (schools, workplaces, ...) in which they can thrive, and that these environments then reinforce these traits thereby magnifying initial differences between people.

\section{DISCUSSION}

\section{Tentative conclusion}

After reviewing the evidence on explanation of health inequalities, and after assessing the possible mechanisms through which genetic determinants could exercise their influence, the most plausible set of hypotheses seems to relate to the genetic determinants of personal attributes that influence intergenerational social mobility, such as cognitive ability, personality, and bodily and mental fitness. It is reasonable to assume that some of the interindividual variation in these attributes is attributable to variations in genotype, and it is reasonable to assume that these attributes affect both social mobility and adult health status. Therefore, genetic determinants of these attributes may play a part, albeit a rather distal and probably modest role, in the explanation of health inequalities.

At this point in time, there is very little empirical evidence on the specific genes that might be involved, although some gene variants have been implicated and more will certainly be proposed in the near future. A research agenda that would address this set of hypotheses would include (1) studies of the determinants of intergenerational social mobility that try to disentangle the influence of individual characteristics and that of the family and wider social environment, (2) studies of the genetic determinants of individual characteristics influencing social mobility that try to identify the specific gene variants involved, and (3) studies of differences in prevalence of these gene variants between adults of different socioeconomic groups, and of the contribution of these differences to the (multivariate) explanation of health inequalities among adults.

It is important to note that the tentative conclusion mentioned above applies to socioeconomic inequalities in general measures of health. The role of genetic factors in explaining other types of health inequalities, for example, by gender or ethnicity, is outside the scope of this paper. The conclusion may also be different for inequalities in specific diseases. If a genetically co-determined disease increases the risk of downward social mobility, as may be the case for schizophrenia and other diseases of adolescence, the disease itself will produce differences between socioeconomic groups in the genetic predisposition for that disease. In the latter case, however, saying that genetic factors "explain" socioeconomic inequalities in the prevalence of that disease would seem to be rather a void statement.

\section{Risks and potential benefits of this research agenda}

Many health inequalities researchers fear that an undue emphasis on the role of genetic factors may distract policymakers from taking the necessary environmental measures to tackle socioeconomic inequalities in health. Recent debates in the US about the possibility that genetic variations in intelligence have become the main determinant of variations in the attainment of social positions (after the publication of the controversial book The Bell Curve $e^{54}$ ), do indeed illustrate that such data may be used to argue that inequalities are irremediable or in any case inevitable. ${ }^{55}$ It is important therefore to carefully identify and weigh the possible risks and benefits of research into the genetics of health inequalities.

On the basis of previous discussions about the ethics of research on behavioural genetics, ${ }^{475657}$ three types of risks can be identified. (1) The first risk relates to using scarce public research funds on the genetics of health inequalities. If the potential of such research for producing benefits to disadvantaged groups would be low, and it certainly is in the short term, then spending money on such research could be seen to redirect money away from safer investments in research on environmental determinants. (2) The second risk relates to the effect that such research and its findings could have on public attitudes towards health inequalities. If it would be shown that health inequalities are partly attributable to differences between socioeconomic groups in genotype, the public may be induced to believe (erroneously) that that part is irremediable, and this may then contribute to fatalistic attitudes among the general public and among policymakers. These beliefs could also lead to increased feelings of powerlessness among disadvantaged people themselves. If disadvantaged people would be shown to be different in relevant aspects of their genetic make up, this could also lead to stigmatisation or discrimination. (3) The third risk relates to ethically undesirable intervention options that research into the role of genetic factors in health inequalities could lead to. Apart from a possible shift of attention away from (presumably more effective) environmental interventions, such research might contribute to a medicalisation of health inequalities, for example, by the development of pharmacological interventions to increase the cognitive abilities of children in disadvantaged families. Perhaps such research could lead to genetic engineering becoming a realistic option to reduce health inequalities. Behavioural genetics has in the past been closely associated with the eugenics movement, and even though current 
researchers may be aversive to eugenics, the results of their research might still lead others to start considering positive or negative eugenics to reduce health inequalities.

On the other hand, research into the genetics of health inequalities also has a number of potential benefits that can be construed in an entirely symmetrical way. ${ }^{475657}$ (1) Whether investigating the role of genetics in health inequalities will increase or decrease the financial resources available for health inequalities research, is entirely dependent on where the funds for such new research come from. There have been considerable increases in financial resources available for biomedical research in several industrialised countries, and if health inequalities researchers could tap some of these research funds, the effect could be an increase of funds available for health inequalities research. (2) It is not certain that more attention to genetic determinants will have a negative effect on the attitudes of the public towards health inequalities: perhaps, if research findings are carefully framed, positive changes may occur. Medicalisation of social problems could perhaps lead to less public disapproval and even to a mobilisation of altruistic feelings. Genetic disadvantage could be seen to interfere with the principle of equal opportunity, and to demand remedial action. (3) What if research into genetic determinants would lead to a drug that helps children in disadvantaged families to improve their congitive abilities and their school performance, or to develop personality traits that are better adapted to societal demands, and to increase the likelihood of developing into happy, healthy, and well to do adults? You could argue that it is difficult to raise ethical objections to such intervention options, or even that it is mandatory to perform such research if there would be a real possibility that such intervention options will be created.

It is difficult, if not impossible, to weigh these risks and potential benefits. Research in this area is almost nonexistent, and all arguments are therefore necessarily speculative. If research on the genetic determinants of health inequalities is conducted, however, it is important to put into place some safeguards that would minimise the risks. The Nuffield Council on Bioethics' report on Behavioural Genetics could serve as a basis for developing such safeguards: "We note that it is important that those who fund research in this area should (...) fund research of a high calibre, should be transparent about their funding practices, and should be aware of the potential for the abuse and misinterpretation of results. In addition, we recommend that research sponsors who intend to focus strategic funding in this area should pay careful attention to public concerns about the research and its application." ${ }^{47}$

\section{Concluding remark}

Some have argued that in an ideal world, in which environmental barriers to educational achievement have been removed completely, inequalities in educational achievement will entirely depend upon individual, innate characteristics. ${ }^{58}$ In this view, research into the importance of genetic factors can be compatible with a strong commitment to further reducing environmental barriers to the educational achievements of children from disadvantaged families. Similarly, it could be argued that in an ideal world, in which all environmental determinants of health have been

\section{Policy implications}

If research on genetic determinants of socioeconomic inequalities in health is to be conducted, it is important to put in place a number of safeguards that minimise the risks. removed, all differences in health between socioeconomic groups will be the result of genetic differences. Clearly, we are still very far from this ideal world, and the need for further environmental measures to reduce health inequalities is by no means diminished by doing some research on genetic determinants.

\section{ACKNOWLEDGEMENTS}

A first draft of this paper has been presented at a conference on Public Health Genetics in Bielefeld (Germany), 19-21 February 2004. The author thanks Professor Angela Brand for inviting him to this conference, and for asking him to develop his thoughts on the genetics of health inequalities. A second draft of this paper has been commented on by Professor Dorret Boomsma, Professor Neil Holtzman, Professor Eero Lahelma, and Dr Karri Silventoinen. Their comments were highly appreciated and helped the author to improve the paper, but any remaining errors are his own.

Funding: none.

Conflicts of interest: none declared.

\section{REFERENCES}

1 Mackenbach JP, Kunst AE, Cavelaars AEJM, et al. The EU Working Group on Socioeconomic Inequalities in Health. Socioeconomic inequalities in morbidity and mortality in Western Europe. Lancet 1997;349:1655-9.

2 Sihvonen AP, Kunst AE, Lahelma E, et al. Socioeconomic inequalities in health expectancy in Finland and Norway in the late 1980s. Soc Sci Med 1998;47:303-15.

3 Dahlgren G, Whitehead M. Policies and strategies to promote equity in health. Copenhagen: World Health Organisation, 1992.

4 Mackenbach JP, van de Mheen $\mathrm{H}$, Stronks K. A prospective cohort study investigating the explanation of socioeconomic inequalities in health. Soc Sci Med 1994;38:299-308.

5 Marmot M, Wilkinson RG, eds. Social determinants of health. Oxford: Oxford University Press, 1999

6 Whitehead M, Diderichsen F, Burström B. Researching the impact of public policy on inequalities in health. In: Graham $\mathrm{H}$, ed. Understanding health inequalities. London: Open University Press, 2000.

7 Calafell F, Malats N. Basic molecular genetics for epidemiologists. J Epidemiol Community Health 2003;57:398-400.

8 Malats N, Calafell F. Basic glossary on genetic epidemiology. J Epidemiol Community Health 2003;57:480-2.

9 Malats N, Calafell F. Advanced glossary on genetic epidemiology. J Epidemiol Community Health 2003;57:562-4.

10 Mackenbach JP, Bakker MJ, Kunst $A E$, et al. Socioeconomic inequalities in health in Europe: an overview. In: Mackenbach JP, Bakker MJ, eds. Reducing inequalities in health: a European perspective. London: Routledge, 2002.

11 Davey Smith G, Blane D, Bartley M. Explanations for socioeconomic differentials in mortality: evidence from Britain and elsewhere. Eur J Public Health 1994;4:131-44.

12 Bartley M. Health inequality: an introduction to theories, concepts and methods. Cambridge: Polity Press, 2004.

13 Blane D, Bartley M, Davey Smith G. Disease etiology and materialist explanations of socioeconomic mortality differentials. Eur J Public Health 1998;7:385-91.

14 Lynch JW, Davey Smith G, Kaplan GA, et al. Income inequality and mortality: importance to health of individual income, psychosocial environment or material conditions. BMJ 2000;320:1200-4.

15 Brunner E, Marmot M. Social organization, stress and health. In: Marmot M, Wilkinson RG, eds. Social determinants of health. Oxford: Oxford University Press, 1999.

16 Bosma H, Peter R, Siegrist J, et al. Two alternative job stress models and the risk of coronary heart disease. Am J Public Health 1998;88:68-74.

17 Cavelaars AEJM, Kunst AE, Geurts JJM, et al. Educational differences in smoking: an international comparison. BMJ 2000;320:1102-7.

18 Davey Smith G, Brunner E. Socioeconomic differentials in health: the role of nutrition. Proc Nutr Soc 1997;56:75-90.

19 Holme I, Helgeland A, Hiermann I, et al. Physical activity at work and at leisure in relation to coronary risk factors and social class. Acta Med Scand 1981;209:277-83.

20 Lynch JW, Kaplan GA, Salonen JT. Why do poor people behave poorly? Variation in adult health behaviours and psychosocial characteristics by stages of the socioeconomic lifecourse. Soc Sci Med 1997;44:809-19.

21 Marmot MG, Davey Smith G, Stansfeld S, et al. Health inequalities among British civil servants: the Whitehall II study. Lancet 1991;337:1387-93.

22 Schrijivers C, Stronks K, van de Mheen HD, et al. Explaining educational differences in mortality: the role of behavioral and material factors. Am J Public Health 1999;89:535-40.

23 Heath A. Social mobility. Glasgow: Fontana, 1981

24 Ganzeboom HBG, Luijkx R, Treiman DJ. Intergenerational class mobility in comparative perspective. Research on Social Stratification and Mobility 1989;9:3-79.

25 Erikson R, Goldthorpe JH. The constant flux: a study of class mobility in industrial societies. Oxford: Oxford University Press, 1992. 
26 Benzeval M, Judge K. Income and health: the time dimension. Soc Sci Med 2001;52:1371-90.

27 Wadsworth MEJ. Serious illness in childhood and its association with later-life achievement. In: Wilkinson RG, ed. Class and health; research and longitudinal data. London: Tavistock, 1986.

28 van de Mheen H, Stronks K, Schrijvers C, et al. The influence of adult ill-health on occupational mobility and mobility into and out of employment in the Netherlands. Soc Sci Med 1999;49:509-18.

29 Blane D, Davey Smith G, Bartley M. Social selection: what does it contribute to social class differences in health? Sociology of Health and Illness 1993;15:1-15.

30 Bartley M, Plewis I. Does health-selective mobility account for socioeconomic differences in health? Evidence from England and Wales, 1971 to 1991. $J$ Health Soc Behav 1997:38:376-86.

31 West $\mathbf{P}$. Rethinking the health selection explanation for health inequalities. Soc Sci Med 1991;32:373-84.

32 Goldman N. Social inequalities in health. Disentangling the underlying mechanisms. Ann N Y Acad Sci $2001 ; 954: 118-39$

33 Judge TA, Higgins CA, Thoreson CJ, et al. The big five personality traits, general mental ability, and career success across the lifespan. Person Psychol 1999;52:621-52.

34 Lounsbury JW, Sundstrom E, Loveland JM, et al. Intelligence, "big five" personality traits, and work drive as predictors of course grade. Person Indiv Diff 2003;35:1231-9.

35 Power C, Fogelman K, Fox J. Health and social mobility during the early years of life. Q J Soc Affairs 1986;2:397-413.

36 Nystrom Peck AM, Vagerö D. Adult body height, self-perceived health and mortality in the Swedish population. J Epidemiol Community Health 1989;43:380-4.

37 Droomers M, Schrijvers CTM, Casswell S, et al. Occupational level of the father and alcohol consumption during adolescence; patterns and predictors. $J$ Epidemiol Community Health 2003;57:704-10.

38 Pulkki L, Kivimäki M, Keltikangas-Järvinen L, et al. Contribution of adolescen and early adulthood personality to the inverse association between education and cardiovascular risk behaviors: prospective population-based cohort study. Int J Epidemiol 2003;32:968-75.

39 Kuh D, Ben-Shlomo Y, eds. A life course approach to chronic disease epidemiology. Oxford: Oxford University Press, 1997.

40 Davey Smith G, ed. Health inequalities: life course approaches. Bristol: Policy Press, 2003.
41 Lynch JW, Kaplan GA, Cohen RD, et al. Childhood and adult socioeconomic status as predictors of mortality in Finland. Lancet 1994;343:524-7.

42 Davey Smith G, Hart C, Blane D, et al. Life-time socioeconomic position and mortality: prospective observational study. BMJ 1997;314:547-52

43 Power C, Matthews S, Manor O. Inequalities in self-rated health: explanations from different stages of life. Lancet 1998;351:1009-14.

44 Vrijheid M, Dolk H, Stone D, et al. Socioeconomic inequalities in risk of congenital anomaly. Arch Dis Child 2000;82:349-52.

45 Bouchard TJ. Genetic and environmental influences on adult intelligence and special mental abilities. Hum Biol 1998;70:257-9.

46 Plomin R, Spinath F. Intelligence: genetics, genes, and genomics. J Person Soc Psychol 2004;86:112-29

47 Nuffield Council on Bioethics. Genetics and human behaviour; the ethical context. London: Nuffield Council on Bioethics, 2002.

48 Atkinson RL, Atkinson RC, Smith EE, et al. Introduction to psychology. $11^{\text {th }}$ ed. Fort Worth: Harcourt Brace Jovanovich College Publishers, 1993.

49 Plomin R, DeFries JC, McClearn GE, et al. Behavioral genetics. 4th ed. New York: Worth, 2001.

50 Silventoinen K. Determinants of variation in adult body height. J Biosoc Sci 2003;35:263-85.

51 Arends N, Johnston L, et al. Polymorphism in the IGF-1 gene: clinical relevance for short children born small for gestational age (SGA). J Clin Endocrinol Metab 2002;87:2720.

52 Vaessen N, Janssen JA, et al. Association between genetic variation in the gene for insulin-like growth factor-1 and low birthweight. Lancet 2002;359:1036-7.

53 Holtzman NA. Genetics and social class. J Epidemiol Community Health 2002;56:529-35.

54 Herrnstein RJ, Murray C. The Bell curve: intelligence and class structure in American life. New York: Free Press, 1994.

55 Two views of the Bell curve. "Breaking the last taboo", Bouchard TJ. "Soff science with a neoconservative agenda", Dorfman DD. Contemporary Psychology, 1995;40. http://www.apa.org/journals/bell.html.

56 Reiss MJ. The ethics of genetic research on intelligence. Bioethics 2000;14:1-15.

57 Newson A, Williamson R. Should we undertake genetic research on intelligence? Bioethics 1999;13:327-42.

58 Bartels M, Rietveld MJH, Baal GCM van, et al. Genetic and environmental influences on the development of intelligence. Behav Genet 2002;32:237-49. 